\title{
Characterization of Some Cement Samples of Nepal Using FTIR Spectroscopy
}

\author{
Suman Lal Shrestha \\ Department of Chemistry, Patan Multiple Campus, Tribhuvan University, Lalitpur, Nepal
}

*Corresponding Author: Suman Lal Shrestha, Department of Chemistry, Patan Multiple Campus, Tribhuvan University, Lalitpur, Nepal

\begin{abstract}
Cement is one of the most vital ingredients to the construction industries since it forms glue that holds concrete together and it plays a significant role in determining the cost of concrete, its environmental impact and durability, although it comprises only less than 15\% of the mass of the concrete. FTIR spectroscopic study was carried out for three different branded Nepali ordinary Portland cement (OPC) collected from the local cement dealers of Patan city of Kathmandu valley (Nepal) to characterize their constituent properties in this study. The properties of the locally available cements in Nepal can be determined quickly and cost effectively using a simple method of FTIR spectra analysis to known whether the available cement samples are in good condition or not. The property of the cement sample of Brand-2 was found to be deteriorated due to hydration as compared to other two cement samples of Brand-1 and Brand-3 used in this study.
\end{abstract}

Keywords: Ordinary Portland cement, Absorption peak, Infrared active, Water/cement ratio.

\section{INTRODUCTION}

Cement is a heterogeneous fine grained material consists mainly of four solid phases of tricalcium silicate $\left(\mathrm{C}_{3} \mathrm{~S} ; 3 \mathrm{CaO} . \mathrm{SiO}_{2}\right)$, dicalcium silicate $\left(\mathrm{C}_{2} \mathrm{~S} ; 2 \mathrm{CaO} \mathrm{SiO}_{2}\right)$, tricalcium aluminate $\left(\mathrm{C}_{3} \mathrm{~A}\right.$; $\left.3 \mathrm{CaO} . \mathrm{Al}_{2} \mathrm{O}_{3}\right)$ and tetracalcium alumino ferrite $\left(\mathrm{C}_{4} \mathrm{AF} ; 4 \mathrm{CaO} . \mathrm{Al}_{2} \mathrm{O}_{3} . \mathrm{Fe}_{2} \mathrm{O}_{3}\right)$ [1] and these chemical components contain various infrared active functional groups. More than 3.4 billion tonnes of cement were produced annually worldwide in the year of 2013 and it was estimated a four-fold increase in the annual production of the cement to the year 2050 [2]. There is no indication that the cement production will be decreased.

The ordinary Portland cement is made by firing raw materials- limestone, clay minerals, sand and iron minerals at around $1500^{\circ} \mathrm{C}$ in a rotary kiln and a series of chemical reaction take place at this temperature and the clinker synthesized. The clinker is cooled, mixed with setting regulators (e.g. gypsum) grounded to a fine powder to obtain the cement [3]. During hydration of the ordinary Portland cement, calcium silicate hydrate $(\mathrm{C}-\mathrm{S}-\mathrm{H})$ gel and calcium hydroxide, $\mathrm{Ca}(\mathrm{OH})_{2}$, are formed from silicates phases and ettringite $(\mathrm{AFt})$, monosulphate $(\mathrm{AFm})$ are formed from aluminate phases [4]. The C-S-H, a major hydration product is the main strength forming phase in the cement paste. The versatility of ordinary Portland cement (OPC) has warranted it continuous interest for the last 150 years [5] and it is expected to draw such interest well into the future. The OPC has now plainly established itself as one of the commodity materials and the mainstay of the construction industry [6, 7]. The OPC is a widely used as a binder in construction industries and it is the most common type of cement around the world. Cement is not a well-defined material since it contains a variety of chemical compositions and additives. Improving the cement within concrete is an essential part of addressing the concerns of concrete durability, maintenance and environmental issues.

It is said that the most frequently used analytical technique for the characterization of such construction materials is X-ray diffraction, thermal analysis and microscopic techniques. Nowadays, infrared and other spectroscopic techniques have become as a useful, non-destructive and easy technique to study the phase composition of initial but also the evolved materials due to their 
exposure to the climatic conditions. The infrared spectroscopy is used both to gather information about the structure of compounds and as analytical tool to assess in qualitative and quantitative analysis of mixtures.

Cement contains several chemical components that contain various functional groups, such as $\mathrm{Si}-\mathrm{O}$, $\mathrm{SO}_{4}{ }^{2-}, \mathrm{H}_{2} \mathrm{O}, \mathrm{OH}^{-}, \mathrm{Al}-\mathrm{O}$ and $\mathrm{CO}_{3}{ }^{-}$, which are infrared active. The absorbed infrared wavelengths of the functional groups are dependent on the chemical surroundings of the group. In recent years, one of the very suitable and easy techniques for characterization of the different types of cement is FTIR spectroscopy. The absorbed infrared wavelengths of the functional groups are dependent on the chemical surroundings of the group. Hence, shifting of the absorption bands of the functional groups, for example, the crystalline clinker phase is altered to the water containing amorphous hydration phases. Infrared spectroscopy is therefore a suitable tool to provide information about the hydration of cement. Therefore, FTIR spectroscopic technique is becoming a quantitative or/and semi-quantitative methods nowadays, which makes it possible to estimate the amounts or relative amounts of the constituents in different brands of cement samples. There will be shifts of the absorption bands of the functional groups e.g. the crystalline clinker phases is altered to the water containing, amorphous hydration phases. Therefore, FTIR spectroscopy is therefore a suitable tool to provide information about the hydration of cement and it is also a quantitative/semi-quantitative method, which makes it possible to estimate the amounts or relative amounts of the constituents in the samples. The FTIR spectra of the cement provide its hydration products [8]. It is meaningful to mention here that it is not only the position of the peak that is relevant; the shape and correlation to other peaks are also important in the interpretation. The influence of different waters on cement was studied with the help of X-band microwave technique [9]. It was investigated the effects of cement type, cement content and water to cement ratio level on the sea water resistance of concrete [10]. In this context, the main objective of this study is to characterize three cement samples collected from the local market of Kathmandu, Nepal using FTIR spectroscopic technique.

\section{MATERials AND MethodS}

Three different branded commercial ordinary Portland cement (OPC) samples were collected from local dealers of Patan of Kathmandu valley for their Fourier transform Infrared (FTIR spectroscopic analysis in this study. The collected cement samples were thoroughly mixed with $\mathrm{KBr}$ and hand grounded to fine powder using agate mortar. The fine power of the sample was made pellet and characterization of the cement sample specimens were qualitatively determined using FTIR-A217053 machine and the FTIR spectra was recorded at Nepal Academy of Science and Technology (NAST).

\section{RESULTS AND DISCUSSION}

FTIR spectra of the powder form of the collected three different branded OPC cement of Patan city were taken to identify their functional groups and the results of the FTIR spectra are shown in Figs 13. The FTIR absorption peak at $3642 \mathrm{~cm}^{-1}$ is assigned to the $\mathrm{O}-\mathrm{H}$ stretching of $\mathrm{Ca}(\mathrm{OH})_{2}$ formed [11]; [12]; [13]; [14] and the intensity of this peak is generally increased with the hydration time. However, two different branded cement samples of the Brand-1 and Brand-3, except Brand-2 sample used in this study did not show a wide absorption peak in the region of $3000-3700 \mathrm{~cm}^{-1}$ which indicates that these two cement samples of the Brand-1 and Brand-3 analyzed here does not contain a large amount of water molecule, but the cement sample of Brand-2 sample has a very broad absorption band between this region as sown in Fig. 2, because symmetric and asymmetric stretching ( 01 and 03 ) of the $\mathrm{O}-\mathrm{H}$ vibrator of the water molecules show a wide absorption peak in this wave number region. A nearly diminished small absorption peak at $1625 \mathrm{~cm}^{-1}$ for the cement samples of Brand-1 and Brand-2 as shown in Figs 1 and 3, is due to the deformation mode $\mathrm{H}-\mathrm{O}-\mathrm{H}$ (v2) of absorbed molecular water by cement. These results revealed that among these collected three different branded cement samples of Katmandu market, only two cement samples of the Brand- 1 and Brand- 3 contained a very small amount of moisture or nearly assumed to be non-hydrated sample. 


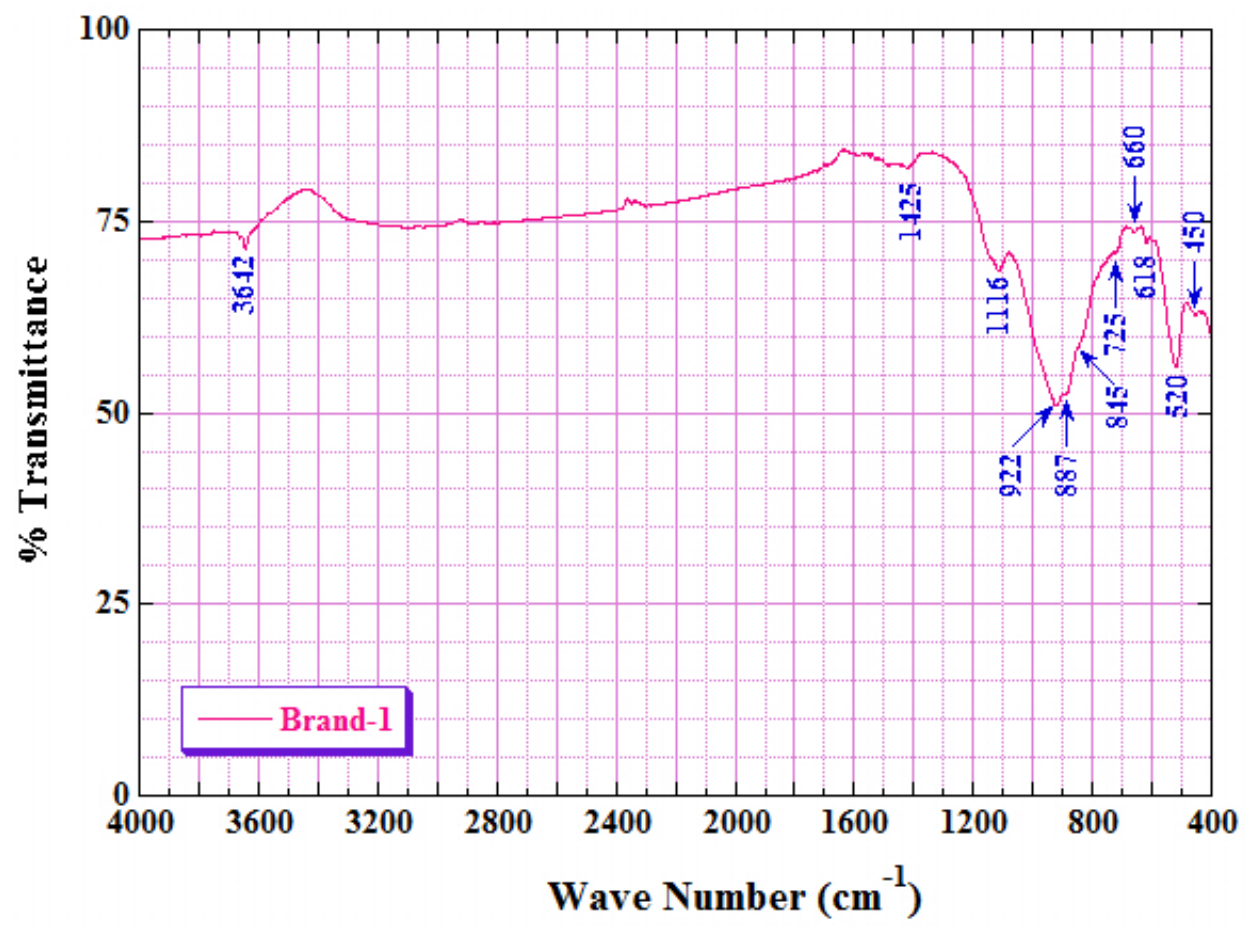

Figure1. FTIR spectra of the OPC cement sample of Brand-1

A sharp FTIR absorption peak in the region of $1105-1116 \mathrm{~cm}-1$ is mostly due to the present of sulfate ions in the cement sample. Similarly, the absorption peak in the region of 1600-1700 is assigned for the bending mode of $\mathrm{H}_{2} \mathrm{O}$ molecule which is clearly shown for the cement sample of Brand-2 as shown in Fig. 2, although the absorption peak at this region is completely diminished for the Brand-1 sample as shown in Fig. 1. A strong FTIR absorption peak around $920-925 \mathrm{~cm}^{-1}$ is due to $\mathrm{Si}-\mathrm{O}$ asymmetric stretching vibration of $\mathrm{C}_{3} \mathrm{~S}$ and/or $\mathrm{C}_{2} \mathrm{~S}$. Out-of-plane $\mathrm{Si}-\mathrm{O}$ bending $\left(v_{4}\right)$ and in-plane $\mathrm{Si}-\mathrm{O}$ bending $\left(v_{2}\right)$ are observed around $520 \mathrm{~cm}^{-1}$ and $450 \mathrm{~cm}^{-1}$, respectively. These peaks assignments are in good agreement with those reported in the previous studies [1]; [3]; [8]; [13]; [14].

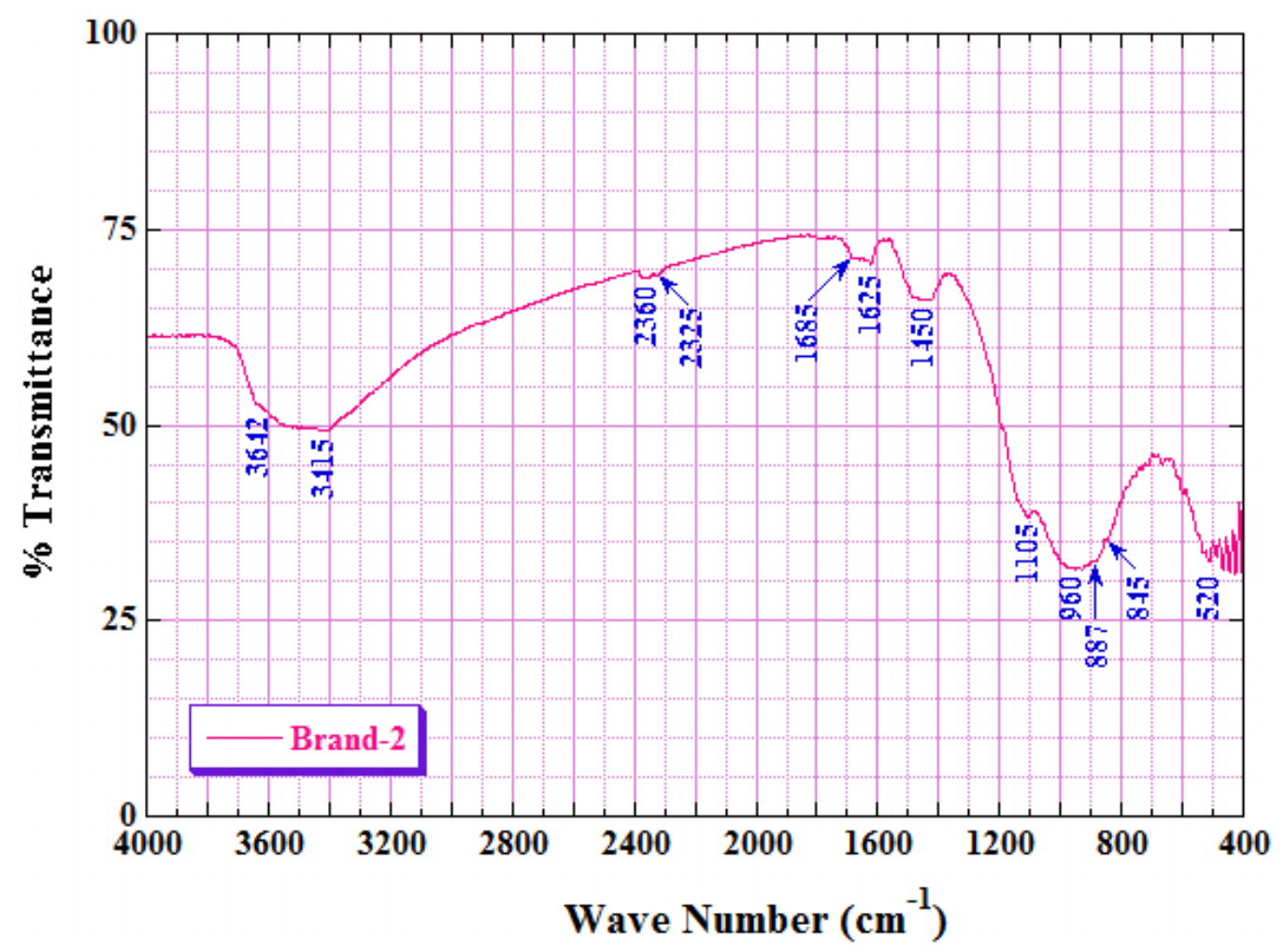

Figure2. FTIR spectra of the OPC cement sample of Brand-2 


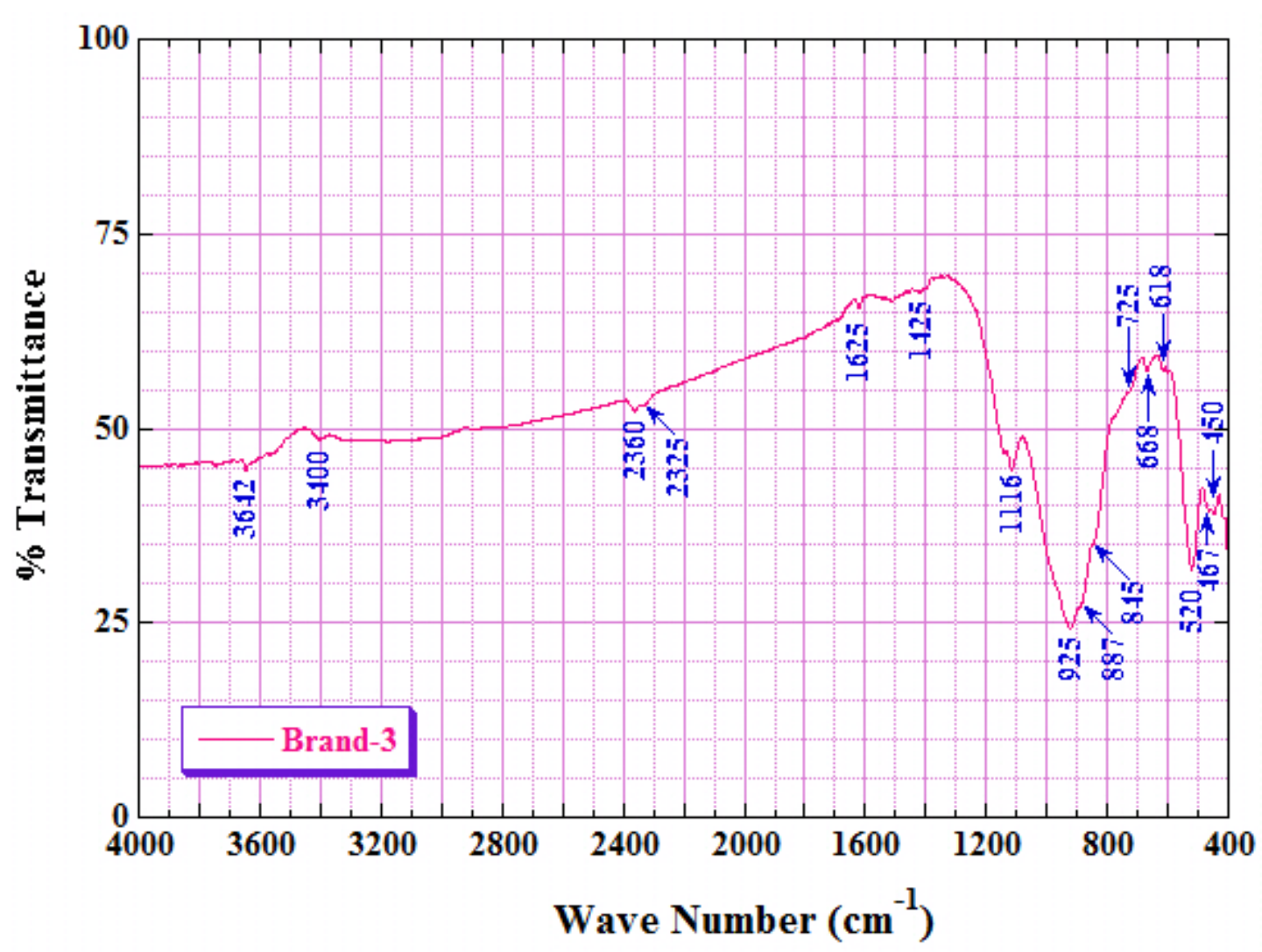

Figure3. FTIR spectra of the OPC cement sample of Brand-3

The absorption peaks at 2360 and $2325 \mathrm{~cm}^{-1}$ should be of carbonate radical in OPC sample and the similar result was also reported in previous work for other materials than cement [15]. It is meaningful to mention here that a common feature of the FTIR spectra band around $2350 \mathrm{~cm}^{-1}$ is due to carbon dioxide [16]. On the other hand, main differences between the hydrated and non-hydrated cement samples is the displacement of stretching mode of Si-O (v3) from $925 \mathrm{~cm}^{-1}$ absorption peak in the non-hydrated cement to $970 \mathrm{~cm}-1$ in the hydrated one [14]. In the present study, FTIR absorption peak for the cement samples of Brand-1 and Brand-3 show at $922 \mathrm{~cm}^{-1}$ and $925 \mathrm{~cm}^{-1}$, respectively, as sown in Figs 1 and 3, although this region FTIR absorption peak for the Brand-2 sample is found at $960 \mathrm{~cm}^{-1}$ as shown in Fig. 2. These results revealed that the collected Brand-2 cement sample is more hydrated than other two cement samples of the Brand-1 and Brand- 3 as a result it can be said that the Brand-2 sample's property is deteriorate due to hydrated of the cement sample as compared to other two cement samples used in this study.

\section{CONCLuSion}

The power form of three different branded OPC cement samples collected from three different dealer of Patan city of Kathmandu valley was qualitatively characterized using FTIR analysis in this study and the following conclusions are drawn:

i. The collected Brand-2 cement sample is more hydrated than other two cement samples of Brand- 1 and Brand- 3 used in this study.

ii. It can be said that the property of the cement sample of Brand-2 is deteriorated due to hydration as compared to other two cement samples used in this study.

iii. The property of the cement available in the local dealers of Kathmandu valley including other parts of Nepal can be determined/confirmed using cost-effective and quick methods of FTIR analysis.

\section{ACKNOWLEDGEMENTS}

Author would like to acknowledge to Nepal Academy of Science and Technology (NAST) for FTIR measurements. 


\section{REFERENCES}

[1] Govindarajan, D. and Gopalakrishnan, R., Spectroscopic studies on Indian Portland cement hydrated with distilled water and sea water, Frontiers in Science, 1, pp 21-27 (2011). https://doi.org/10.5923/j.fs. 20110101.04

[2] van Oss, H.G., http://minerals.usgs.gov/minerals/pubs/commodity/cement/mcs-2013-cemen.pdf (2013) [accessed June 10, 2018]

[3] Fernández-Carrasco, L., Torrens-Martín, D., Morales, L.M. and Martínez-Ramírez, S., Infrared spectroscopy in the analysis of building and construction materials, in Infrared Spectroscopy- Materials Science, Engineering and Technology (ed. T. Theophile), INTECH Europe, pp 369-382 (2012). https://doi.org/10.5772/36186

[4] Nevillea, M. and Brooks, J.J., Concrete Technology, Addison Wesley Longman Ltd. (1987).

[5] Ylmen, R., Jaglid, U. and Panas, I., Monitoring early hydration of cement by ex-situ and in-situ ATR FTIR- a comparative study, Journal of the American Ceramic Society, 97(11), pp 3669-3675 (2014). https://doi.org/10.1111/jace.13186

[6] Ylmen, R., Wadsö, L. and Panas, I., Insights into early hydration of Portland limestone cement from infrared spectroscopy and isothermal calorimetry, Cement and Concrete Research, 40, pp 1541-1546 (2010). https://doi.org/10.1016/j.cemconres.2010.06.008

[7] Aitcin, P.-C., Cements of yesterday and today: concrete of tomorrow, Cement and Concrete Research, 30, pp 1349-1359 (2000). https://doi.org/10.1016/S0008-8846(00)00365-3

[8] Trezza, M.A., Hydration study of ordinary Portland cement in the presence of zinc ions, Materials Research, 10 (4), pp 331-334 (2007). http://dx.doi.org/10.1590/S1516-14392007000400002

[9] Barathan, S., Govindarajand, Sivakumar, G. and Raghuk, Microwave study of hydration of cement with different waters, Indian Journal of Pure and Applied Physics, 44, pp 334-338 (2006).

[10] Yigiter, H., Yaxici, H. and Aydin, S., Effect of cement type, water/cement ratio and cement content on seawater resistance of concrete, Building Environment, 42, pp 1770-1777 (2007).

[11] Oriol, M. and Pera, J., Pozzolanic activity of metakaolin under microwave treatment, Cement and Concrete Research, 25(2), pp 265-270 (1995). https://doi.org/10.1016/0008-8846(95)00007-0

[12] Dutta, D., Bordolor, D. and Bothakur, P., Hydration of Portland cement clinker in the presence of carbonaceous materials, Cement and Concrete Research, 25(5), pp 1095-1102 (1995). https://doi.org/ 10.1016/0008-8846(95)00104-K

[13] Jo, B.W., Sikandar, M.A., Chakraborty, S. and Baloch, Z., Strength and durability assessment of Portland cement mortars formulated from hydrogen-rich water, Advances in Materials Science and Engineering, 2017, pp 1-10 (2017). https://doi.org/10.1155/2017/2526130

[14] Bensted, J. and Varna, S.P., Some applications of IR and Raman, Spectroscopy in cement chemistry, Part III: Hydration of Portland cement and its constituents, Cement Technology, 5(5), pp 440-450 (1974).

[15] Moenke, H.H.W., Silica, the three-dimensional silicates, borosilicates and beryllium silicates, in: Infrared Spectra of Minerals (ed. V. C. Farmer), Mineralogical Society, London, pp 365-382 (1974).

[16] Elsass, F. and Oliver, D., Infrared and electron spin resonance studies of clays representative of the sedimentary evolution of the basin of Autun, Clay Minerals, 13, pp 299-305 (1978).

Citation: Suman Lal Shrestha, "Characterization of Some Cement Samples of Nepal Using FTIR Spectroscopy", International Journal of Advanced Research in Chemical Science (IJARCS), vol. 5, no. 7, pp. 19-23, 2018. http://dx.doi.org/10.20431/2349-0403.0507004

Copyright: (C) 2018 Authors. This is an open-access article distributed under the terms of the Creative Commons Attribution License, which permits unrestricted use, distribution, and reproduction in any medium, provided the original author and source are credited. 